\title{
Guidelines for Safe Routine Dental Practice During the COVID-19 Pandemic
}

Perspectives from the Dental Training Department, Ministry of Health, Bahrain

ABSTRACT

The Dental Postgraduate Training Department at the Ministry of Health, Bahrain, is committed to raising the standards of care provided to our patients through postgraduate education, and the provision of evidence-based guidance for dental professionals.

We believe that this set of guidelines will prepare the dental professionals to resume and continue their routine dental procedures in primary care dental clinics during the pandemic.

The purpose of developing these guidelines is to ensure the provision of best practices in safe environment for the dental health care professionals and the patient.

\section{Keywords}

Dental practice, COVID-19, Restoration of services
${ }^{1}$ Gowri Sivaramakrishnan, ${ }^{2}$ Fatema AlSulaiti, ${ }^{3}$ Muneera Alsobaiei

${ }^{1}$ Specialist Prosthodontist and Dental Tutor, Dental Training Department, Ministry of Health, Bahrain, ${ }^{2}$ Consultant Dentist, Dental Training Department, Ministry of Health, Bahrain, ${ }^{3}$ Consultant Restorative Dentist, Chief of Dental Training Department, Ministry of Health, Bahrain

Gowri.sivaramakrishnan@gmail.com

Cite as:

Sivaramakrishnan, G., Alsulaiti, F., Alsobaiei, M. (2021) Guidelines for safe routine dental practice during COVID-19 pandemic. The Physician vol 7; Issue 1: 1-9 ePub 28.02.2021 DOI

https://doi.org/10.38192/1.7.1.2

Article Information

Submitted 17.02.2021

ePub 28.02.2021

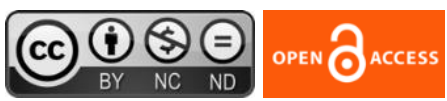

ISSN 2732-513X (Print) ISSN 2732 - 5148 (Online) 


\section{INTRODUCTION}

The purpose of developing these guidelines is to ensure the provision of best practices in safe environment for the dental health care professionals and the patient. It is a credit to our profession that we were able to work collaboratively and constructively to reach to a consensus on this issue. We sincerely hope that there is equality in strictly adhering to this guideline, to ensure the delivery of dental treatment resuming routine dental health services. Bahrain has reported more than 15,000 cases of COVID-19 by June 2020 and it is on the rise. Dentists have been identified to be at high risk of infection and transmission due to the nature of their practice. ${ }^{[1]}$ Hence, the Ministry of Health in Bahrain temporarily suspended all aerosol generating and invasive dental procedures from March 2020, and only emergency and aerosol free dental procedures were available to address dental emergencies. Recently countries across the world, including Bahrain, are working on a roadmap to support reopening and safe functioning of their dental practices. The priority now remains safety, and this guide provides a framework for dental teams to ensure a risk assessment based strategy for safe treatment of patients at their practice level. In this document we propose that the dental practices across the World adhere to these guidelines to integrate safe and effective return to practice. As well as these guidelines will ensure safe and effective practice monitoring in the future, if a similar pandemic arises in the future in a safe environment and prevent further cross infection amongst the professionals and patients.

We hope that these guidelines will form a basis for further training of dental professionals and staff, which helps in effective practice monitoring. There is great deal of concern among dentists and dental practices regarding the transmission of various microbial diseases, due to close contact between the dentist and the patient. The recent pandemic of COVID-19 has created greater concern, and strict infection control guidelines must be in place before

\section{TRANSMISSION ROUTES OF COVID-19 AND SIMILAR VIRAL INFECTIONS IN DENTAL PRACTICES:}

The figure illustrates the possible transmission route of COVID-19 in dental practices. This can be applied to other previously reported infections like SARS (Severe Acute Respiratory Syndrome) and MERS (Middle Eastern Respiratory Syndrome) as well. The incubation period of most of these reported viral infections is reported to be around 2-14 days. ${ }^{[2]}$ This longer asymptomatic incubation period leads to transmission of the infection, which is often unnoticed. (Figure 1) $^{[3]}$

\section{INFECTION CONTROL IN DENTAL PRACTICES:}

The goal of a successful infection control program is to break the chain of infection (Figure $2^{\text {) }}{ }^{[3,4]}$ by consistently practicing protocols which would prevent the infectious agent moving from one host to another and preventing cross infection.

\section{The infection control program should include:}

- Rapid identification and source control of symptomatic patients (masking and separation)

- Strict adherence to respiratory and hand hygiene practices

- Training staff on correct use of PPE (Personal protective equipment)

- Rigorous environmental cleaning and disinfection of surfaces and equipment.

\section{STANDARD OR UNIVERSAL PRECAUTIONS APPLIED AT THREE LEVELS:}

Standard or Universal precautions are a set of infection control practices used to prevent transmission of diseases that can be acquired by contact with blood, body fluids, non-intact skin (including rashes), and mucous membranes.

${ }^{[4]}$ These measures are to be used when providing care to all individuals, whether or not they appear infectious or symptomatic. These guidelines emphasize the use of standard precautions in three levels as shown in Figure 3 .

Level 1: Pre-treatment Precautions: 


\section{Visual Triage:}

Visual triage includes the use of a checklist to perform initial screening of patients. This form given in Table 1 is developed by the National Taskforce for Combating the Coronavirus (COVID-19) in Bahrain, to evaluate the risk of exposure. This must be done prior to entry of the patient into the dental clinic, possibly in the waiting area. This has to be undertaken by trained dental staff that follow strict infection control guidelines involving the use of Personal protective equipment.

\section{Pre-procedural Mouth rinses:}

Aerosols are liquid or solid particles of less than 50 micrometers in diameter that stay suspended in the air for extended periods. Spatter are airborne particles larger than $50 \mathrm{~mm}$ in diameter that are too heavy to become suspended in the air for longer periods. This has a tendency to settle on surfaces ${ }^{[4,5]}$ Many dental procedures, such as use of the ultrasonic scalers, slow- and high-speed hand pieces, and 3-way syringes, generate aerosol and spatter. There is evidence that dental aerosol can reach a distance of 1 through 3 meters from its source, causing contamination of distant surfaces. In contrast, spatter reaches shorter distances and settles quickly, which makes dental aerosol a greater concern for oral health care personnel (OHCP), when it comes to airborne contamination $[4,5,6-12]$ Pre-procedural mouth rinses with chlorhexidine, which is readily available in all Primary care dental clinics, has been shown to significantly reduce the number of colony forming units (CFU) ${ }^{[13]}$ The patient should rinse for a minimum of 30 seconds. ${ }^{[13]}$ Hence these guidelines advice the use of chlorhexidine as a pre-procedural mouth rinse for all patients before commencing dental treatment.

\section{Water-line disinfection:}

Dental unit waterlines are 3-4 m flexible, narrow tube made of plastic material. The surface of the tube enhances the biofilm formation. During the course of usage, the biofilm-coated untreated dental unit waterlines allows the microorganism to disperse through the water network and poses a risk to the dentist, dental team, and patients to pathogens. ${ }^{[7]}$ These guidelines suggest any of the combination of below mentioned techniques to prevent contamination through the waterlines.

- Flush waterlines with water for 3-5 minutes every morning before receiving your patient and the at end of the day.

- Flush hand pieces and waterlines for 20 to 30 seconds between patient appointments.

- Independent bottle water systems

- Anti-retraction devices to prevent backflow.

Additionally, dentists can choose the below mentioned techniques to further enhance disinfection of the water lines considering the current pandemic situation.

- Chemical treatment of water using Ethylenediaminetetraacetic acid, sodium hypochlorite, chlorhexidine $\underset{[5,7]}{\text { gluconate, povidine iodine, ethanol, peroxide, phenol, and glutaraldehyde, that are tested in clinical trials }}$

- The use of $10 \%$ sodium hypochlorite for 10 minutes flushing of the waterline has been recommended. ${ }^{[7]}$ However corrosive effects have been reported. So chemical treatment has to be used with caution.

Level 2: Precautions during treatment:

\section{Hand hygiene:}

The appropriate protocol should be adhered by both the patient and the dentist before commencing any procedure as shown in Figure 4. ${ }^{[14]}$

Personal Protective Equipment (PPE): 
Minimum level 3 surgical mask should be used ${ }^{[15]} \mathrm{N}-95$ to be used as a precaution when performing any aerosol generating procedure, or any procedure on a suspected or positive case of COVID-19 or CLI. The appropriate PPE to be used by OHCP is shown in Table 2 .

Importance of using Level 3 surgical mask:

Masks are generally classified into 3 types: low (ASTM Level 1), moderate (ASTM level 2), and high barrier (ASTM Level 3) according to The American Society of Testing and Materials (ASTM). ${ }^{[13]}$ The classification by ASTM is presented in Table 3 with their suggestions for use. According to a study by The Centre for Evidence-Based Medicine, University of Oxford, there is no direct evidence on the utility of $\mathrm{N}-95$ masks for prevention of transmission against COVID-19. However surgical masks level 3 performed similar to respirator masks for prevention against other viral infections. ${ }^{[16]}$ Hence these guidelines suggest the use of $\mathrm{N}-95$ masks as a precaution when performing any aerosol generating procedure, or any procedure on a suspected or positive case of COVID-19 or CLI.

\section{Risk Stratification for Dental procedures:}

The classification by the FGDP (Faculty of General Dental Practice, UK) helps in stratification of risk of the dental procedure being undertaken, based on which, further selection and degree of infection control should be aimed. (Table 4) ${ }^{[17]}$ The guide is not an exhaustive list and only includes a few examples. Both low risk and high risk procedures should only be performed with appropriate level of infection control as discussed in detail above. If an AGP (aerosol generating procedure) is performed in a suspected patient, appointment interval should be lengthened. And every effort should be made to minimize overlapping dental appointments. The minimum suggested fallow time is 15 to 30 minutes. ${ }^{[17]}$

\section{Sequence for putting on and removing PPE:}

The CDC guidelines for donning and doffing PPE should be strictly followed as shown in Figure 5 and Figure 6. ${ }^{[18]}$

\section{Use of aerosol reducing devices:}

These guidelines propose the use of any of the below mentioned techniques to reduce the amount of aerosol generated during AGP's, if it is necessary to be performed to avoid prescription misuse.

1. Prevent contaminated aerosols from escaping the mouth - Using rubber dam during AGPs will reduce the contamination of the aerosols with oral microbial organisms. ${ }^{[8]}$ Saliva ejectors reduce the aerosols escaping the mouth ${ }^{[7,8]}$

2. Prevent contaminated aerosols from escaping the immediate operating site- Aerosols coming out of the mouth are removed with local exhaust ventilation such as high-volume evacuation systems. ${ }^{[10]}$

3. General ventilation- Methods such as avoiding the use of fans that can recirculate the air, to keep windows open at the dental operatory room and use of exhaust fans have been suggested. ${ }^{[10]}$

Level 3: Post treatment Precautions:

After providing dental treatment for a patient it is imperative that correct procedures and protocols are followed to protect staff and all subsequent patients.

These guidelines recommend that:

- Patient should leave the operatory immediately and clean their hands outside the surgery

- Mask should not be removed by the dentist immediately, if an AGP was performed. Strictly adhere to the guidelines for doffing outside the dental operatory in the designated doffing area.

- Sterilization and disinfection protocols for the instruments and the whole operatory should be strictly followed and monitored regularly. 
- Surfaces that cannot be properly pre-cleaned and disinfected must be protected with single use, disposable, barrier material such as plastic or fluid resistant paper. Barriers should be changed between patients.

- $\quad$ Disposable items are single use only items and must be disposed appropriately.

\section{Waste Management:}

Waste in the dental practice should be separated according to its category (medical or non-medical) at the point of generation. Bags and containers for medical waste should be appropriately color coded and labelled as biohazard or medical waste. Standard precautions mentioned above must be used when handling medical waste bags and containers. Medical waste bags and containers must not be overfilled and must not be compacted by hand. Medical waste and hazardous chemical waste (which includes some chemicals and mercury used in dental practice) must never be disposed of at local refuse tips that use compaction of an open landfill. Medical waste and sharps containers must be stored securely before collection by licensed waste contractors for final disposal using approved technologies by licensed/accredited contractors. Extracted teeth once cleaned of visible blood, debris, adherent soft tissues and saliva may be given to the patient. Alternatively, they can be wrapped in paper towel or placed in a disposable cup and covered with setting plaster before disposal in the general waste. The guidelines for waste management that is followed in the Ministry of Health in Bahrain is presented in Figure 7.

\section{ACKNOWLEDGEMENT:}

Author contributions

Author 1,2,3: Contributed to conception, design, data acquisition and interpretation, drafted and critically revised the manuscript

Author 1,2: Contributed to conception, design, data acquisition and interpretation, performed all statistical analyses, drafted and critically revised the manuscript

Author 1,2,3: Contributed to conception, design, and critically revised the manuscript

All authors gave their final approval and agree to be accountable for all aspects of the work.

\section{Compliance with Ethical Standards}

Conflict of Interest: Gowri Sivaramakrishnan declares that she has no conflict of interest. Muneera Alsobaiei declares that she has no conflict of interest. Fatema ALSulaiti declares that he has no conflict of interest.

Funding: No Funding was provided.

Ethical approval: This article does not contain any studies with human participants or animals performed by any of the authors.

Informed consent: For this type of study, formal consent is not required.

\section{REFERENCES:}

1. Lan FY, Wei CF, Hsu YT, Christiani DC, Kales SN. Work-related COVID-19 transmission in six Asian countries/areas: A follow-up study. PLoS One. 2020;15(5):e0233588. Published 2020 May 19. doi:10.1371/journal.pone.0233588

2. Special Expert Group for Control of the Epidemic of Novel Coronavirus Pneumonia of the Chinese Preventive Medicine Association. Zhonghua Liu Xing Bing Xue Za Zhi. 2020;41(2):139-144. doi:10.3760/cma.j.issn.02546450.2020 .02 .002

3. Peng X, Xu X, Li Y, Cheng L, Zhou X, Ren B. Transmission routes of 2019-nCoV and controls in dental practice. Int J Oral Sci. 2020;12(1):9. Published 2020 Mar 3. doi:10.1038/s41368-020-0075-9

4. Sebastiani FR, Dym H, Kirpalani T. Infection Control in the Dental Office. Dent Clin North Am. 2017;61(2):435-457. doi:10.1016/j.cden.2016.12.008

5. Kohn WG, Collins AS, Cleveland JL et al. Guidelines for infection control in dental health-care settings--2003. MMWR Recomm Rep. 2003;52(RR-17):1-61.

6. Meng L, Hua F, Bian Z. Coronavirus Disease 2019 (COVID-19): Emerging and Future Challenges for Dental and Oral Medicine. J Dent Res. 2020;99(5):481-487. doi:10.1177/0022034520914246

7. Garg SK, Mittal S, Kaur P. Dental unit waterline management: historical perspectives and current trends. J Investig Clin Dent. 2012;3(4):247-252. doi:10.1111/j.2041-1626.2012.00135.x 
8. Samaranayake LP, Reid J, Evans D. The efficacy of rubber dam isolation in reducing atmospheric bacterial contamination. ASDC J Dent Child. 1989;56(6):442-444.

9. Holloman JL, Mauriello SM, Pimenta L, Arnold RR. Comparison of suction device with saliva ejector for aerosol and spatter reduction during ultrasonic scaling. J Am Dent Assoc. 2015;146(1):27-33. doi:10.1016/j.adaj.2014.10.001

10. Jacks ME. A laboratory comparison of evacuation devices on aerosol reduction. J Dent Hyg. 2002;76(3):202206.

11. Mousavi MS, Hadei M, Majlesi M, et al. Investigating the effect of several factors on concentrations of bioaerosols in a well-ventilated hospital environment. Environ Monit Assess. 2019;191(7):407. Published 2019 Jun 4. doi:10.1007/s10661-019-7559-0

12. Sawhney A, Venugopal S, Babu GR et al. Aerosols how dangerous they are in clinical practice. Journal of clinical and diagnostic research: JCDR. 2015 Apr;9(4):ZC

13. Marui VC, Souto MLS, Rovai ES, Romito GA, Chambrone L, Pannuti CM. Efficacy of preprocedural mouthrinses in the reduction of microorganisms in aerosol: A systematic review. J Am Dent Assoc. 2019;150(12):1015-1026.e1. doi:10.1016/j.adaj.2019.06.024

14. World Health Organization Hand hygiene practices. Available @ https://www.who.int/gpsc/5may/Hand Hygiene Why How and When Brochure.pdf. Accessed on 18-1-2020

15. Makison Booth C, Clayton M, Crook B, Gawn JM. Effectiveness of surgical masks against influenza bioaerosols. J Hosp Infect. 2013;84(1):22-26. doi:10.1016/j.jhin.2013.02.007

16. The Centre for Evidence-Based Medicine develops, promotes and disseminates better evidence for healthcare. University of Oxford. Available from: https://www.cebm.net/covid-19/what-is-the-efficacy-of-standardface-masks-compared-to-respirator-masks-in-preventing-covid-type-respiratory-illnesses-in-primary-care-staff/ Accessed on 15-6-2020.

17. Implications of COVID-19 for the safe management of general dental practice- A practice guide . Available from https://www.fgdp.org.uk. accessed on 15-6-2020

18. CDC sequence for putting on and removing PPE. Available from https://www.cdc.gov Accessed on 18-1-2021. 


\section{FIGURE LEGENDS:}

Figure 1: Transmission of COVID-19 and similar viruses.

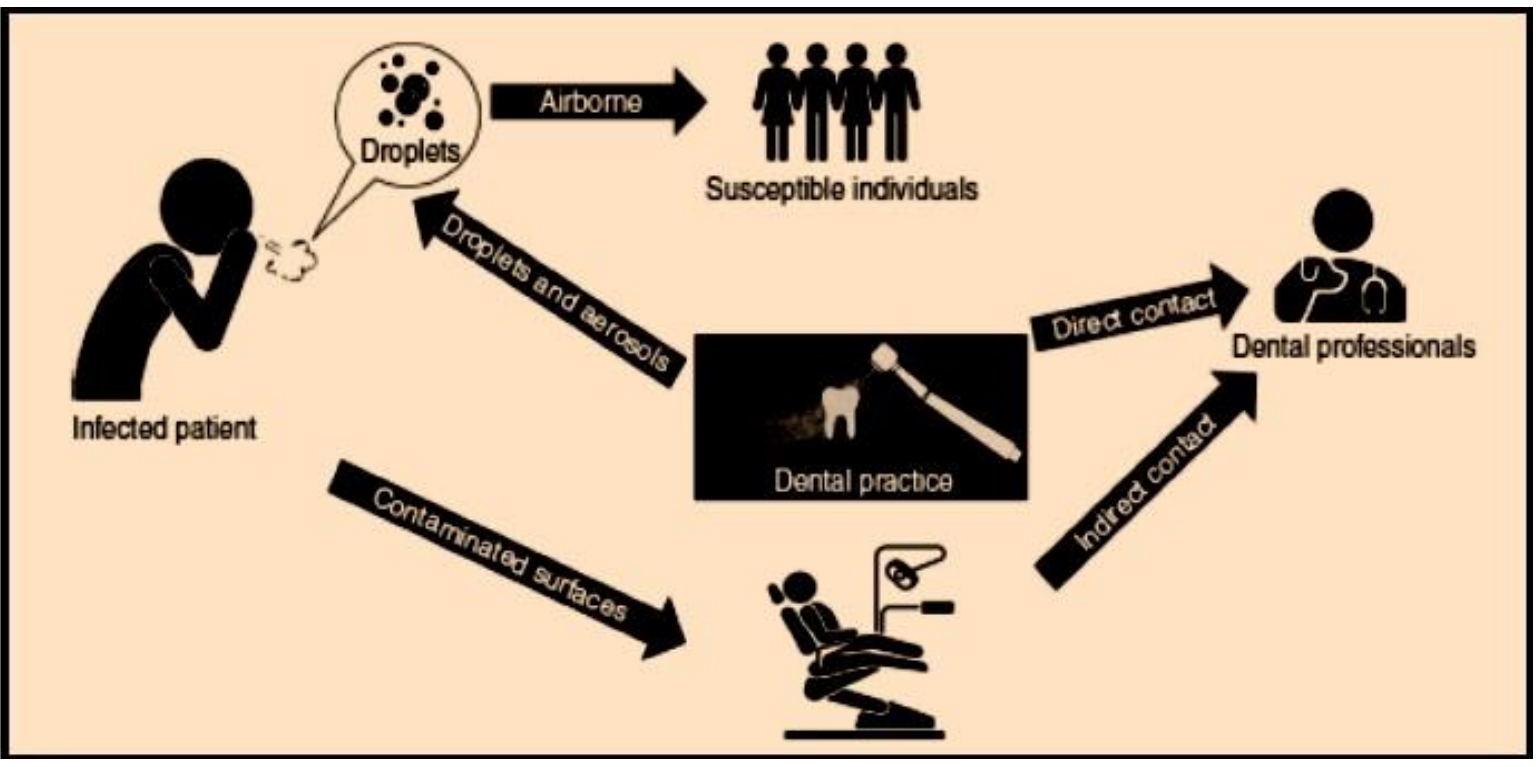

Figure 2: Chain of infection.

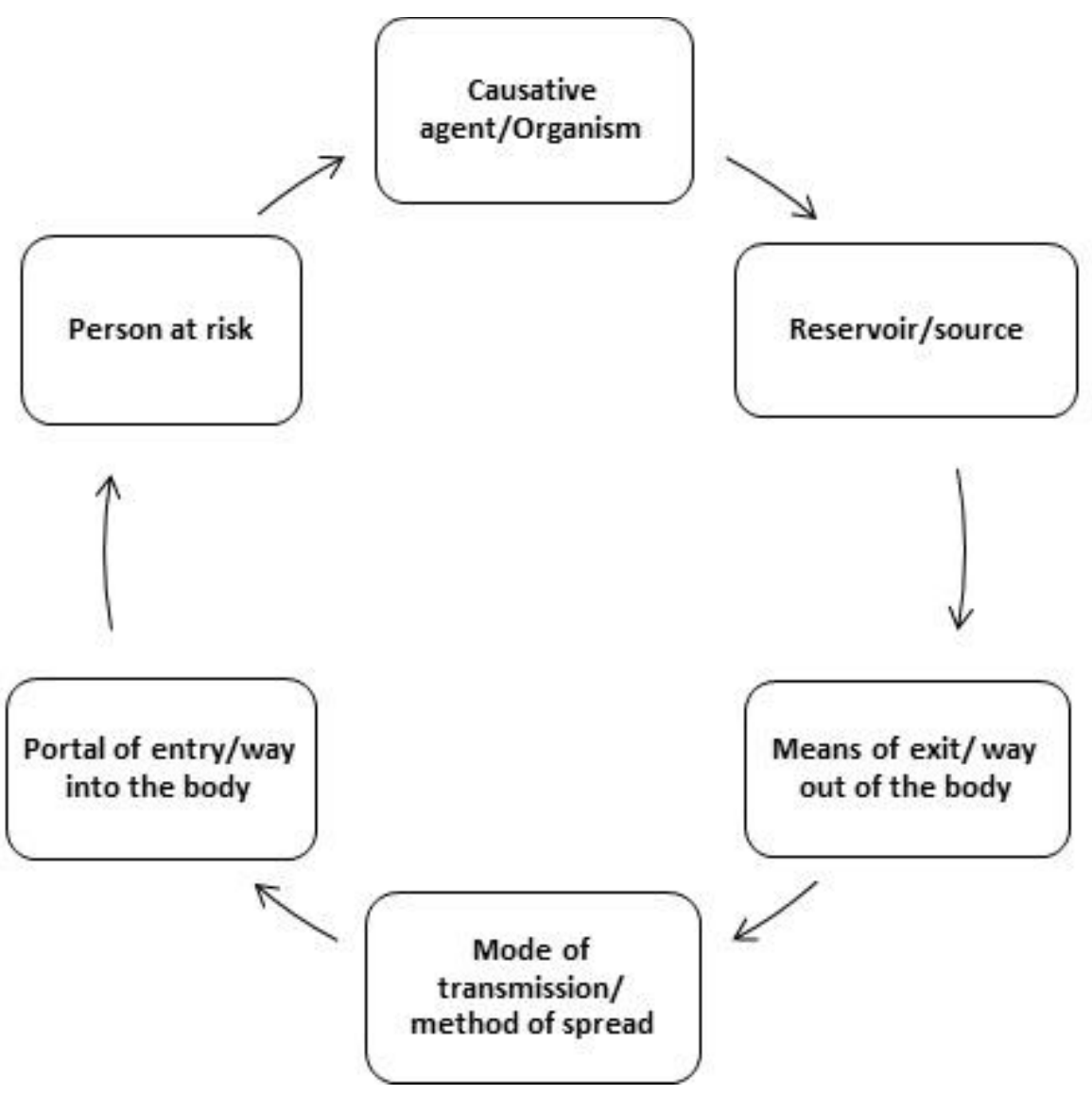


Figure 3: Standard precautions applied at three levels.

Pre-treatment precautions

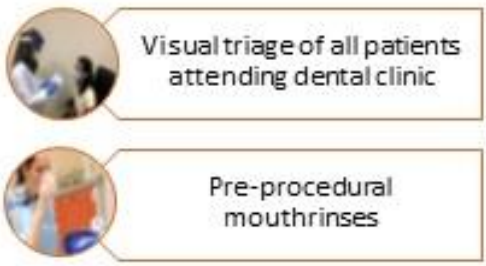

Waterline disinfection
Precautions during treatment
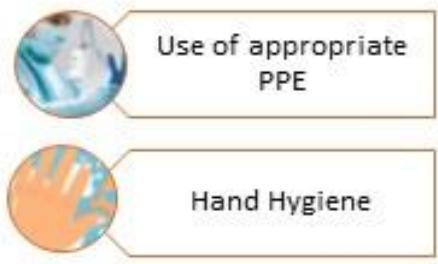

Risk stratification of dental procedures
Post-treatment precautions

Disinfection of the clinics

Sufficient time between patients

Disposal of PPE and waste according to guidelines

Figure 4: Handwashing protocol

\section{How to Handwash?}

WASH HANDS WHEN VISIBLY SOILED! OTHERWISE, USE HANDRUE

Duration of the entire procedure: $40-60$ seconds

0

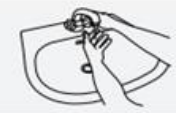

Wet hando weh water;

3

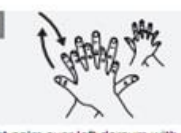

Right paim over leet doraum with
interlaced fingers and vice versat:

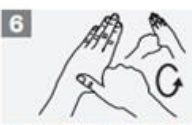

Rotatonal rubbing of left thumb
clabeped in right paim and vice vera:

9

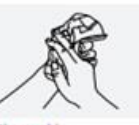

Dry handa thoroughy
with a single cue towes

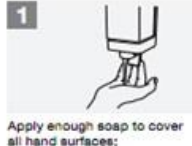

4

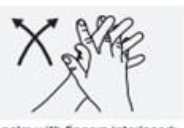

Palm to polim with fingers interisced:

7

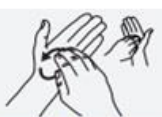

Rotational nubbing, bachwards and
torwards with claseped fingers of night

10

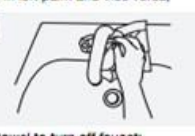

2

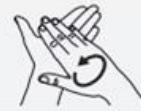

Rub hancla paim to paim;

5

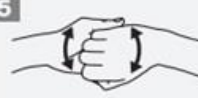

Backs of tingers to opposing paims
whth fingers interlocked:

8

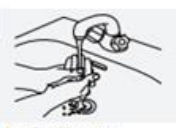

Finse hando with water

11

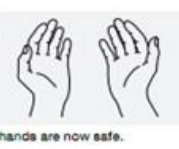

\section{How to Handrub?}

RUB HANDS FOR HAND HYIIENE! WASH HANDS WHEN VISIBLY SOILED (1) Duration of the entire procedure: $20-30$ seconds

i.
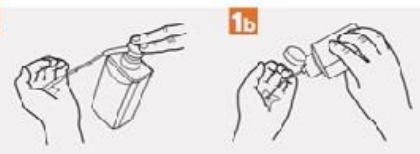

2

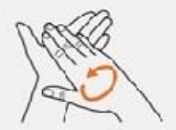

appy a pairfur of tne proovec n a supsec nand, covering all surtaces;

3]

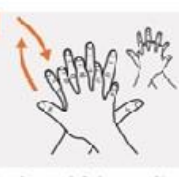

Right psim over left dorsum with
interlaced fingers and vico veras

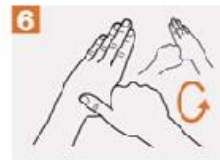

4

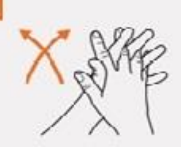

Palm to aalm with fingers irterlaced:

7

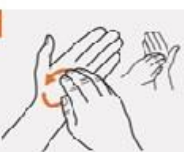

Rotational nobbing of lot thumb
clasped in nignt paim ard vice verse;

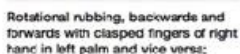


Figure 5: Sequence of putting on PPE

\section{SEQUENCE FOR PUTTING ON PERSONAL PROTECTIVE EQUIPMENT (PPE)}

The type of PPE used will vary based on the level of precautions required, such as standard and contact, droplet or airborne infection isolation precautions. The procedure for putting on and removing PPE should be tailored to the specific type of PPE.

\section{GOWN}

- Fully cover torso from neck to knees, arms to end of wrists, and wrap around the back

- Fasten in back of neck and waist
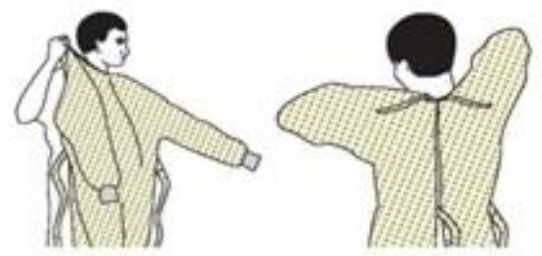

\section{MASK OR RESPIRATOR}

- Secure ties or elastic bands at middle of head and neck

- Fit flexible band to nose bridge

- Fit snug to face and below chin
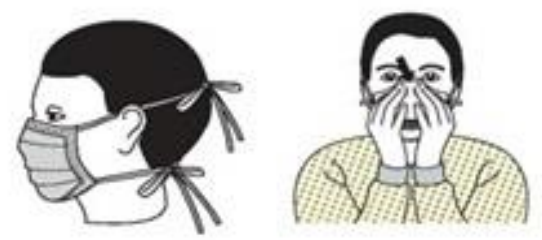

- Fit-check respirator

\section{GOGGLES OR FACE SHIELD}

- Place over face and eyes and adjust to fit

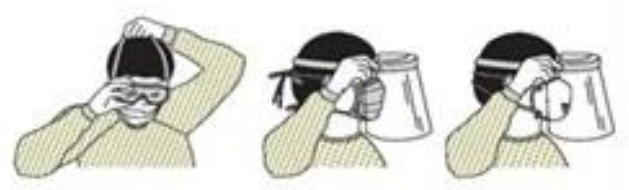

\section{GLOVES}

- Extend to cover wrist of isolation gown

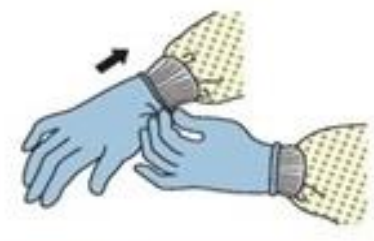

USE SAFE WORK PRACTICESTO PROTECT YOURSELF AND LIMIT THE SPREAD OF CONTAMINATION

- Keep hands away from face

- Limit surfaces touched

- Change gloves when torn or heavily contaminated

- Perform hand hygiene 
Figure 6: Sequence to safely remove PPE

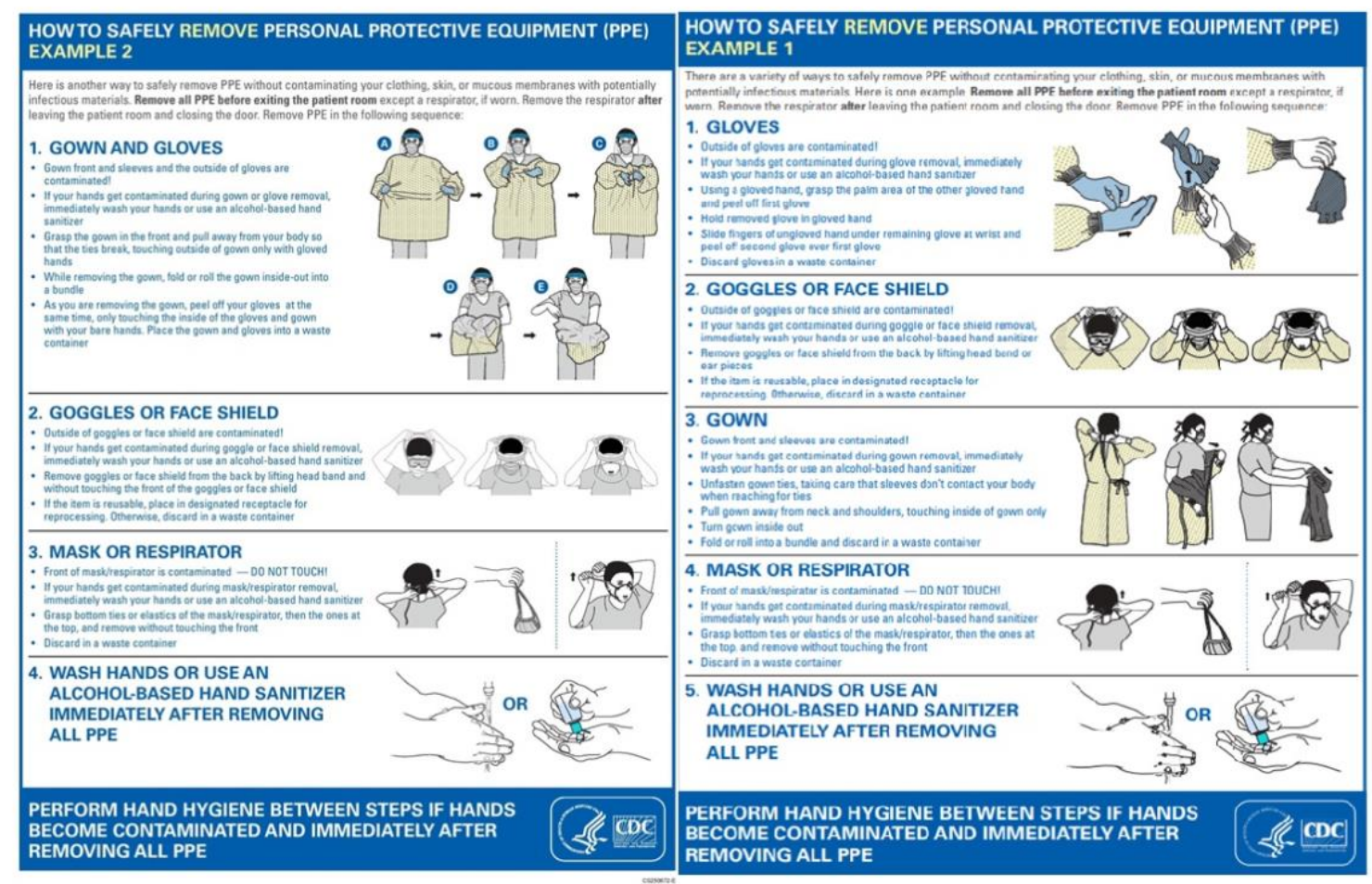


Figure 7: Medical waste segregation chart

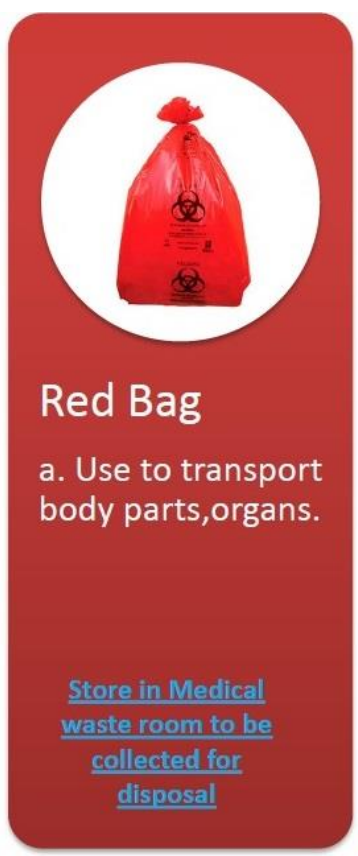

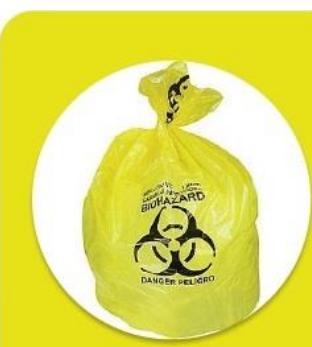

\section{Yellow Bag}

a. Used to dispose infectious waste. b. Containers with blood/body fluids that cannot be emptied.

c. All microbiological waste (specimens, cultures, and stocks of etiologic agents).

. material used for patient care or used by staff (gowns, gloves, suction containers and catheters)

e. Chemotherapy waste.

Store in Medical

waste room to be

collected for

disposal

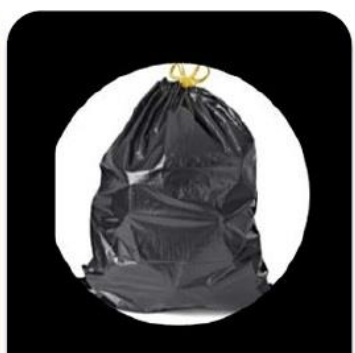

Black Bag

a. Used to dispose of general hospital

waste.

b. Items that would not release (drip)

blood or other potentially infectious materials in a liquid or semi-liquid

state.

d. Laboratory solid waste, not
included in the infectious waste

category.

Dispose into

municipality

containers near the

facility

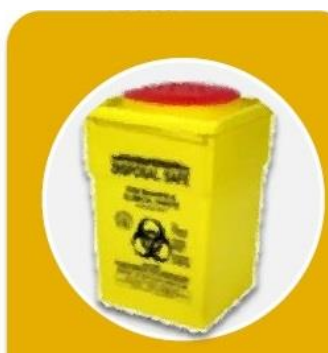

Sharp container

-Used to dispose all needles,

scalpels, pipettes, syringes,

and glass items.

- Replace the sharps container

promptly when the sharps

container is $3 / 6$ filled (and

reaches the fill line)

(Housekeeping Services).

Store in Medical

waste room to be

collected for

disposal 


\section{TABLES;}

Table 1: Visual triage checklist before commencing any dental procedure:

Demographic data of the patient:

\begin{tabular}{|l|l|}
\hline \multicolumn{1}{|c|}{ A. Exposure Risk } & Score \\
\hline $\begin{array}{l}\text { Contact with a confirmed case of COVID19 or CLI* in the last 14days prior to } \\
\text { symptoms onset }\end{array}$ & 3 \\
$\begin{array}{l}\text { Lived or worked in a facility known to be experiencing an outbreak of COVID-19 or } \\
\text { CLI* in the last 14days prior to onset of symptoms }\end{array}$ & \\
\hline B. Clinical signs and symptoms & $\mathbf{4}$ \\
\hline Fever or recent history of fever & $\mathbf{4}$ \\
\hline Cough (new or worsening) & $\mathbf{4}$ \\
\hline Shortness of breath (new or worsening) & $\mathbf{1}$ \\
\hline Headache, sore throat or rhinorrhea & $\mathbf{1}$ \\
\hline Nausea, vomiting and/or diarrhea & $\mathbf{1}$ \\
\hline Chronic renal failure, Chronic heart disease, immunocompromised patient & \\
\hline Total score A+B & \\
\hline
\end{tabular}

If score of $\geq 4$ (high risk category), assess the need for any pharmacological intervention to help with the chief complaint, isolate patient, ask to wear a mask, inform physician for assessment and call 444 . If the score is less than 4 (low risk category), proceed with dental treatment following the guidelines mentioned.

${ }^{*}$ COVID like illness 
Table 2: Appropriate use of PPE:

\begin{tabular}{|c|c|c|c|c|c|}
\hline Setting and people & Surgical mask* & $\begin{array}{c}\text { N-95 mask } \\
\#\end{array}$ & $\begin{array}{c}\text { Eye } \\
\text { googles/face } \\
\text { shield }\end{array}$ & Gown & Gloves \\
\hline \multicolumn{6}{|c|}{ Reception and waiting area } \\
\hline Receptionist & $\mathbf{v}$ & & $\boldsymbol{V}$ & & \\
\hline Visitor & $\mathbf{v}$ & & & & \\
\hline \multicolumn{6}{|c|}{ Clinic area } \\
\hline Dentist & $\sqrt{ }$ & $\sqrt{ }$ & $\mathbf{V}$ & $\boldsymbol{V}$ & $\sqrt{ }$ \\
\hline Dental assistant & $\sqrt{ }$ & $\sqrt{ }$ & $\mathbf{V}$ & $\mathbf{v}$ & $\sqrt{ }$ \\
\hline \multicolumn{6}{|c|}{ Other areas } \\
\hline During Sterilization & $\sqrt{ }$ & & $\mathbf{V}$ & $\mathbf{v}$ & $\sqrt{ }$ \\
\hline Cleaning and sorting & $\mathbf{v}$ & & $\mathbf{V}$ & $\boldsymbol{V}$ & $\sqrt{ }$ \\
\hline
\end{tabular}

Table 3: Mask level and indications:

\begin{tabular}{|l|l|}
\hline \multicolumn{1}{|c|}{ Mask level } & \multicolumn{1}{c|}{ Suggested Procedure by ASTM } \\
\hline Level 1 masks (ASTM low barrier) & $\begin{array}{l}\text { low amounts of blood, fluid, spray and/or aerosol exposure. } \\
\text { Common clinical examples include patient exams, operatory } \\
\text { cleaning, impressions, lab trimming and orthodontic work. }\end{array}$ \\
\hline Level 2 masks (ASTM moderate barrier) & $\begin{array}{l}\text { procedures where moderate to light amounts of fluid, spray } \\
\text { and/or aerosols are produced. Suitable for restoratives, } \\
\text { prophylaxis, sealants, limited oral surgery and endodontic } \\
\text { work }\end{array}$ \\
\hline Level 3 masks (ASTM high barrier) & $\begin{array}{l}\text { procedures with moderate to heavy amounts of blood, fluid, } \\
\text { spray and/or aerosol exposure. High barrier protection is } \\
\text { needed for procedures such as implant placement, crown } \\
\text { preparation, and periodontal or complex oral surgery. }\end{array}$ \\
\hline
\end{tabular}


Table 4: Risk Stratification of dental procedures:

\begin{tabular}{|l|l|l|}
\hline Procedures & Lower risk aerosol exposure & High risk of aerosol exposure \\
\hline Instruments & $\begin{array}{l}\text { Hand scaling instruments Extraction } \\
\text { Forceps/ Elevators 3 in 1 (air-only/water- } \\
\text { only) } \\
\text { Slow speed /electric handpiece (i.e. }<60 \\
000 \text { rpm) } \\
\text { Prophylaxis with pumice (using slow- } \\
\text { speed handpiece/ prophy cup) } \\
\text { Diathermy Denture/ortho adjusting using } \\
\text { slow speed handpiece } \\
\text { Surgical and Implant Handpieces }\end{array}$ & $\begin{array}{l}\text { Ultrasonic scaler (including piezo) } \\
\text { High speed air rotor /electric handpiece (i.e. }>60 \\
000 \text { rpm) Piezo surgical Handpiece } \\
\text { Air polishers 3 in 1 (air and water together) }\end{array}$ \\
\hline $\begin{array}{l}\text { Dental Procedures that may produce } \\
\text { splatter but are unlikely to produce } \\
\text { aerosol particles }<5 \mu \text { m (including use of } \\
\text { powered low velocity instruments) }\end{array}$ & $\begin{array}{l}\text { Dental Procedures that will produce aerosol } \\
\text { particles }<5 \text { im includes use of Powered high } \\
\text { velocity instruments that emit or require aerated } \\
\text { water or irrigants for coolant }\end{array}$ \\
\hline & & \\
\hline
\end{tabular}

